\title{
HBs antigene prevalence in blood donors and the risk of transfusion of hepatitis $B$ at the central hospital of yaounde, cameroon
}

\author{
Dominique Noah Noah ${ }^{1}$, Richard Njouom ${ }^{2}$, Aimé Bonny ${ }^{3}$, Pirsou ${ }^{1}$, J. Meli $^{4}$, M. Biwole Sida ${ }^{5}$ \\ ${ }^{1}$ Central Hospital of Yaounde, Gastroenterology Service, Yaounde, Cameroon; \\ ${ }^{2}$ Centre Pasteur of Cameroon, Virology Laboratory, Yaounde, Cameroon; \\ ${ }^{3}$ Saint Camille Hospital, Cardiology Service, Bry sur Marne, Pitié Salpêtrière Hospital, Paris, France; \\ ${ }^{4}$ Faculty of Medicine and Biomedical Sciences, University of Yaoundé 1, Yaoundé, Cameroon; \\ ${ }^{5}$ Central Hospital of Yaoundé, Faculty of Medicine and Biomedical Sciences, University of Yaoundé 1, Yaoundé, Cameroon. \\ Email: noahnoahd@yahoo.fr
}

Received 17 September 2011; revised 25 October 2011; accepted 3 November 2011.

\section{ABSTRACT}

Parenteral transmission of hepatitis B virus (HBV) during blood transfusion is not insignificant. Although blood transfusion safety has greatly improved over the last 15 years, the transfusion risk of $\mathrm{HBV}$ remains high in developing countries. In the context where blood transfusion safety is limited in some hospitals in Cameroon, the development of good and quality practice for blood donation, based on the use of the most sensitive techniques for the detection of infectious risk of blood donation should be a priority of health authorities. The aim of this paper is to document the epidemiology of $\mathrm{HBV}$ infection in the population of blood donors and to assess the risk of infection during blood transfusions at the Central Hospital of Yaoundé (CHY), Cameroon. Methods: During a seven months period, 1000 volunteer donors were recruited prospectively at the blood bank of the CHY. Those included in the study were people aged from 18 years to 55 years without any particular medical history. Data collection was done through an investigation form. Samples were first analysed at the CHY and then at Centre Pasteur of Cameroon. Results: Of the 1000 samples tested $108(\mathbf{1 0 . 8 \% )}$ were positive for $\mathrm{HBs}$ Ag. The male and the female sex represented $83.1 \%$ and $16.9 \%$ respectively. According to the age groups, $56.2 \%$ were 18 to 27 years, $30.5 \%$ were 28 years to 37 years, $10.4 \%$ were 38 years to 47 years and $29 \%$ were 48 years to 55 years. The 892 negative sera were analyzed for total anti-HBc antibodies of which $75.78 \%$ were positive and $24.56 \%$ negative. The 676 samples positive for anti-HBc antibody were retested for HBs Ag using enzyme immunoassay with a confidence level of $95 \%$, between 52 and 82 positive tests were still positive, a proportion that vary between $7.64 \%$ and $12.14 \%$ $(9.89 \% \pm 2.25 \%)$. Conclusion: The prevalence rate of $10.8 \%$ found in our series is consistent with data in Cameroon. The infectious risk of transmission of HBV among blood donors remains a major problem $(9.89 \% \pm 2.25 \%)$ related to the test used.

Keywords: Infectious Risk; HBV; CHY

\section{INTRODUCTION}

Viral hepatitis B is a major public health problem in the world where the number of people infected is estimated at 2 billion and 350 million for chronic carriers. The $\mathrm{B}$ virus is responsible for approximately 500,000 deaths annually and $75 \%$ of cases of hepatocellular carcinoma $[1,2]$. The hepatitis B virus (HBV) is the second most common carcinogen agent known to humans after smoking [3]. HBV is also the first cause of hepatocellular carcinoma in South-East and Sub-Saharan Africa [4]. In Cameroon, HBV is by far considered as the leading cause of liver cirrhosis before chronic alcoholism [5]. The most common means of transmission of HBV are from mother to child, parenteral and sexual transmission. Besides these means of transmission, parenteral transmission of $\mathrm{HBV}$ during blood transfusion is not insignificant. In Greece, a study carried out in 1996 showed that the rate of post transfusion hepatitis was higher than the prevalence of hepatitis C [6]. In Sub-Saharan Africa, the prevalence of HBs Ag among blood donors ranges between $9.2 \%$ in the DRC [7] and $10.7 \%$ in Cameroon [8]. The transfusion risk is even higher if the donation is made during the window period when the HBV infection 
cannot be detected by conventional screening techniques. This risk is considerably reduced by adding to the serological screening, a viral genome screening. In this context, routine laboratory diagnosis appears to be a means of preventing HBV infection risk to be implemented in the frame work of blood safety that stands as a strong aspect to minimize the transmission post transfusion hepatitis [6]. This blood safety has greatly improved over the last 15 years in industrialized countries, due to the development of more efficient and innovative screening techniques. The prevalence rates of transfused viral infections have significantly decreased in these countries to reach negligible levels. Generally, in developing countries and in sub-Saharan Africa in particular, the registered prevalence reflects some deficiencies related to blood safety in blood banks and blood centres of hospitals. While most infections are detected incidentally during a blood donation, for example, other infections are diagnosed in the hospital at the beginning of a complication.

In Cameroon, the prevalence of HBV infection among blood donors is estimated at $10.7 \%$ [8]. In this context of limited blood safety, the development of good and quality practice of blood donation based on the use of the most sensitive techniques for detecting the risk of infection should be a health priority being aware of the fact that approximately 14,000 blood donations are made annually at the Central Hospital of Yaoundé (Sources blood bank). In this paper, we propose to document the epidemiology of HBV infection in Cameroon by determining the prevalence of HBs Ag in the population of blood donors and assessing the risk of infection of HBV during blood transfusions at the Central Hospital of Yaoundé (CHY), Cameroon.

\section{MATERIALS AND METHODS}

A prospective study carried out between July 2007 and January 2008 (7 months) was used to examine blood samples from voluntary donors recruited at the blood bank of the CHY. Were included in the study participants with the following criteria: Age between 18 and 55 years; Took a meal before donating blood; Blood test before blood donation; Date of last blood donation > 3 months; Date of the last or next menses $>10$ days; Satisfactory or normal physical condition; Body weight $>50 \mathrm{~kg}$.

Was excluded from the study, participants who did not meet the inclusion criteria listed above and those with the following peculiarities: Lactating Women; Patient who had undergone a surgery; Patient who had undergone a blood transfusion during the last twelve months, Patient with chronic disease (hypotension or hypertension, diabetes, heart disease, asthma, epilepsy, etc.); Pa- tient in poor physical condition (emaciation, weakness, jaundice, dyspnoea, pallor, obesity, etc.).

Data was collected from the patients recruited in the study using a questionnaire after having read and signed informed consent. The random sampling method was used. The minimum sample size was calculated according to the Lorenz formula with a prevalence of $\mathrm{HBV}$ in the general population estimated at $14.85 \%$. The detection of HBs Ag in all blood samples was performed at the CHY laboratory using the immuno-chromatographic technique (Hexagon ${ }^{\circledR}$ HBs Ag). Sera samples testing negative immuno-chromatographic HEXAGON ${ }^{\circledR}$ technique were further tested in the Virology Laboratory of Centre Pasteur of Cameroon using the Monolisa ${ }^{\circledR}$ technique for the detection of anti-HBc antibodies. Finally, the samples positive for anti-HBc antibodies were retested for the detection of HBs Ag by enzyme immunoassay (ELISA Monolisa ${ }^{\circledR}$ HBs Ag Ultra). Data entry was done using the Excel ${ }^{\circledR}$ 2007. Descriptive analysis was performed through the calculation of proportions for qualitative variables (frequency, percentage), means and standard deviations for continuous variables. The different frequency comparisons were made using Chi-square test (x2) of Pearson and Fisher test when necessary.

\section{RESULTS}

\subsection{Characteristics of Donors}

From July 2007 to January 2008, a total of 1000 blood donors were recruited prospectively at the $\mathrm{CHY}$, with an average daily recruitment of 6.49 volunteers. Old donors were 825 with $82.5 \%$ of donations and new donors 175 with $17.5 \%$ of the donations. According to sex we had 831 (83.1\%) men and 169 (16.9\%) women.

The most represented age group was 18 years - 27 years with 562 (56.2\%) donors, followed by the 28-37 years age group with 305 (30.5\%) donors and that of 38 years - 47 years with 104 (10.4\%) donors; the least represented being the 48 years - 55 years age group with 29 (2.9\%) donors (Table 1).

\subsection{Prevalence of HBs Antigen by the Rapid Immuno-Chromatographic Technique}

Of the 1000 donor samples tested in the CHY, 108 were positive to the rapid test (Hexagon ${ }^{\circledR} \mathrm{HBs}$ Ag), with a seroprevalence of $10.80 \% \pm 1.92 \%$. Male donors $(95 \%$ or $87.96 \%)$ were more infected than female (13\% or $12.04 \%)$ $(\mathrm{P}<0.005)$. The prevalence of HBs Ag according to age groups was as follows: 18 years - 27 years: $63(58.33 \% \pm$ $1.92 \%) ; 28$ years - 37 years: $36(33.33 \% \pm 1.92)$ and 38 years - 47 years $9(08.33 \% \pm 1.92 \%)$. The 48 years - 55 years age group was not represented in this seroprevalence. 


\subsection{Prevalence of Total Anti-HBc Antibodies by Immunoassay MONOLISA $^{\circledR}$}

It was determined from the 892 samples that were negative to the rapid test. According to sex, there were: 592 (66.37\%) males and $84(9.42 \%)$ females. According to age group, we had: 362 (40.58\%) for 18 years -27 years, $225(25.22 \%)$ for 28 years -37 years, $75(8.41 \%)$ for 38 years - 47 years and $13(1.46 \%)$ for 48 years -55 years. The percentage of samples tested positive for total anti-HBc antibodies was $75.78 \% \pm 2.81 \%$. Similar to the rapid test, the proportion of positive sera was higher in men than in women $(\mathrm{p}<0.005)$ (Table 2).

\subsection{Prevalence of HBs Ag by ELISA}

The 676 samples positive for the anti-HBc antibodies, were retested in search of HBs Ag using enzyme immunoassay and, at a confidence level of 95\%. Between 52 and 82 tests were still positive with a proportion that varies between $7.64 \%$ and $12.14 \%$. So with an error margin of $5 \%$ the risk of infection transmission of hepatitis $\mathrm{B}$ in the $\mathrm{CHY}$ is $9.89 \% \pm 2.25 \%$.

\section{DISCUSSION}

\subsection{Prevalence of $\mathrm{HBs} \mathrm{Ag}$}

The prevalence of HBs Ag in our study was $10.8 \%$. This result is consistent with that of the study by Mbanya et al. (10.7\%) performed in a population of blood donors at the Yaoundé University Hospital [8]. This prevalence is comparable with that of the general population in Cameroon between $10 \%$ and $15 \%$ [9].

\subsection{Characteristics of Donors}

The population of our study is relatively young (mean age 36.5 years, with the extremes of 18 and 55 years). The most represented sex is the male with $83.9 \%$. This has been shown by several studies including that conducted by Mbendi Nlombi C. et al. in three hospitals in East Kinshasa in the DRC on the prevalence of $\mathrm{HBs} \mathrm{Ag}$ among blood donors [7]. A survey at the Institut de Veille Sanitaire carried out in 2003-2004 in France showed that chronic carriers of HBV were predominantly males (men were seven times more represented than women), in situations of social insecurity (3 times as many beneficiaries of the Universal Mutual Fund) (CMUC) and born in sub-Saharan Africa (5 times more than those born in Europe), Middle East (2.5 times) and Asia (2 times) [10]. There are several reasons for this predominance in males. Firstly, cultural reasons that pre-define gender to a type of activity. On the other hand, men have few contra-indications for blood donation, such as menstruation, pregnancy, lactation [11].

Moreover, the proportion of males most affected is between 18 and 27 years. These results could be explained by the fact that the major contamination of hepatitis $\mathrm{B}$ is during birth, and infection may progress for 20 to 25 years in a subtle manner.

Table 1. Distribution of blood donors by sex and according to old or new donor.

\begin{tabular}{|c|c|c|c|c|c|c|}
\hline \multirow{3}{*}{ Age group } & \multicolumn{4}{|c|}{ Sex } & \multirow{2}{*}{\multicolumn{2}{|c|}{ Total }} \\
\hline & \multicolumn{2}{|c|}{ Males } & \multicolumn{2}{|c|}{ Females } & & \\
\hline & new & old & new & old & new & old \\
\hline 18 - 27 years & 66 & 389 & 11 & 96 & 77 & 485 \\
\hline 28 - 37 years & 58 & 207 & 9 & 31 & 67 & 238 \\
\hline 38 - 47 years & 22 & 63 & 5 & 14 & 27 & 77 \\
\hline 48 - 57 years & 3 & 23 & 1 & 2 & 4 & 25 \\
\hline \multirow{2}{*}{ Total } & 149 & 682 & 26 & 143 & 175 & 825 \\
\hline & \multicolumn{2}{|c|}{$831(83.1 \%)$} & \multicolumn{2}{|c|}{169 (16.9\%) } & \multicolumn{2}{|c|}{1000 (100\%) } \\
\hline
\end{tabular}

Source: Blood bank CHY \& CPC.

Table 2. Distribution of HBs Ag negative donors to the rapid test according to age group, sex and the seroprevalence of total anti HBc antibodies.

\begin{tabular}{|c|c|c|c|c|c|c|c|c|c|}
\hline \multirow{3}{*}{ Age group } & \multicolumn{6}{|c|}{ Sex } & \multirow{2}{*}{\multicolumn{3}{|c|}{ Total }} \\
\hline & \multicolumn{3}{|c|}{ Male } & \multicolumn{3}{|c|}{ Female } & & & \\
\hline & number & Anti-HBcT+ & $\%$ & number & Anti-HBcT+ & $\%$ & number & Anti-HBcT+ & $\%$ \\
\hline 18 - 27years & 455 & 322 & $36.10 \%$ & 49 & 40 & $4.48 \%$ & 503 & 362 & $40.58 \%$ \\
\hline 28 - 37years & 238 & 194 & $21.75 \%$ & 31 & 31 & $3.48 \%$ & 269 & 225 & $25.22 \%$ \\
\hline 38 - 47years & 84 & 62 & $6.95 \%$ & 18 & 13 & $1.46 \%$ & 102 & 75 & $8.41 \%$ \\
\hline 48 - 57years & 13 & 13 & $1.46 \%$ & 4 & 0 & $0.00 \%$ & 18 & 13 & $1.46 \%$ \\
\hline Total & 790 & 592 & $66.37 \%$ & 102 & 84 & $9.42 \%$ & 892 & 676 & $75.78 \%$ \\
\hline
\end{tabular}

Source: Blood bank CHY \& CPC. 
According to the criterion of old or new donor, we had $82.5 \%$ of old donors and $17.5 \%$ of new donors. These results can be explained by the fact that the CHY has successfully implemented a loyalty program for voluntary donors program with the help of the Red Cross. Otherwise, the major reason for blood donation is to support a friend or family member [11].

\subsection{Transmission and Evolution of $\mathrm{HBV}$}

Diop T. et al. [12] in a study in Senegal showed that vertical transmission from mother to child represents 50 to $75 \%$ of all transmissions of the B virus. Other factors equally play a role during birth: the use of contaminated material during clamping of the umbilical cord, circumcision and scarification rituals. The major problem of infection with hepatitis B virus is the risk of developing chronic complications. If $5 \%$ - $10 \%$ of immunocompetent adults are likely to become chronic carriers after infection, this percentage is much higher among infants born to mothers carrying HBs Ag (close to 90\%). In case of prenatal contamination immune tolerance phase is extended and the transition to the immune response phase is rare and late. Half of chronic carriers develop cirrhosis and/or with a risk of progression to HCC, which varies from $2 \%$ to $3 \%$ per year [6]. Some studies have shown that in chronic carriers of HBs Ag, HCC is likely to occur in approximately $40 \%$ of cases before the stage of cirrhosis $[4,12]$.

\subsection{Role of Blood Transfusion}

Blood transfusion is a major risk of HBV infection in most health facilities in Cameroon, first because of the increased demand for blood to treat certain emergency conditions such as acute anemia due to malaria, sickle cell anemia, traffic accidents (with the current inflation motorcycle taxis), different gynecology bleeding... and also the lack of blood banks in most rural health facilities. If the blood safety techniques have infinitely reduced the risk of contamination through transfusion in developed countries, this progress must be weighed against the continuous emergence of new pathogens potentially transmissible during transfusion and the disparity with safety blood transfusions in developing countries where resources are insufficient for a baseline screening for infectious diseases in donors.

\subsection{Risk of Infection Transmission}

In this study we aimed at evaluating in a central level university hospital, the risk of infection transmission after blood transfusion related to the type of reagent usually used. We did not consider patient samples that tested positive since they were immediately eliminated. The infectious risk of transmission of hepatitis B through transfusion of a pine of blood declared negative to HBs Ag was $9.89 \% \pm 2.25 \%$ at a confidence level of $95 \%$. This rate is close to the prevalence of HBs $\mathrm{Ag}$ in the general population of Cameroon [9]. Considering the fact that the blood bank of the CHY delivers an average more than 14,000 pines of blood yearly, this implies that there are between 1070 and 1670 induced infections of HBs Ag annually. The Immunochromatographic method (rapid test) used in the CHY is less sensitive than the immunoassay used at Centre Pasteur of Cameroon (CPC) which served as a reference test or immunoradiometry (IRMA) recommended in countries such as Tunisia [13]. The 892 sera that tested negative for HBs Ag were retested by the immunoenzymatic method for the detection of anti-HBc antibodies. Two hundred and sixteen of these tests were negative for anti-HBc antibodies corresponding to naive subjects in whom vaccination was recommended. The interpretation of 676 samples had to undergo a search for HBs Ag by a more sensitive method as was the case in our study to detect false negatives.

The consensus conference of the Canadian Association for the Study of Liver (CASL) [14] held in Toronto on 4 and 5 January 2007 made routine screening and monitoring of patients by using PCR methods a recommendation. The aim was not only to achieve a high degree of sensitivity of screening but also to harmonize the monitoring of these patients. In all cases, the interpretation of anti-HBc antibodies should suggest three scenarios. It could be a self-resolving HBV infection with undetectable levels of anti-HBs antibodies. In fact several years after an acute HBV infection, the anti-HBs antibodies may become undetectable indicating a resolution of the condition with the persistence of anti-HBc only, which is the most consistent marker of a previous contact with virus [15]. Secondly, the lack of detection of markers other than anti-HBc antibodies may also correspond to a certainty of hepatitis B [15]. This is also the case in our study where we found an infection rate of hepatitis B ranging from $7.64 \%$ to $12.14 \%$. FKI-Berrajah L. et al., in his work has shown that during the evolution of chronic hepatitis $\mathrm{B}$, the rate of $\mathrm{HBs}$ Ag could drop to very low levels which would make it undetectable. The spontaneous loss of HBs Ag is described in 0.5 to $5 \%$ of patients with chronic hepatitis $\mathrm{B}$ [13]. Finally the detection of anti-HBc antibodies in the absence of detection of another marker could represent false positive results. In fact the use of immunoradiometric method for 160 sera previously tested for anti-HBc antibody by ELISA showed negative results on 19 sera suggesting the possibility of false positive results [16,17].

\section{CONCLUSIONS}

The prevalence rate of $10.8 \%$ found in our study popula- 
tion is consistent with data in Cameroon (between 8 and $12 \%)$. The risk of transmission of $\mathrm{HBV}$ among blood donors remains a major problem at the $\mathrm{CHY}, 9.89 \% \pm$ $2.25 \%$ to a confidence level of $95 \%$. Considering the natural history of hepatitis $\mathrm{B}$, especially its evolution to chronic liver cirrhosis and hepatocellular carcinoma, blood banks should be established in most hospitals and especially assuring safety of blood transfusion using immunoradiometric (IRMA) or immunoassay as in most countries.

\section{REFERENCES}

[1] Frexinos, J., Buscail, L., et al. (2003) Hépato-gastroentérologie proctologie. MASSON, Paris, 5, 489.

[2] Trepo, C. and Zoulim, F. (2009) Traitement de l’hépatite B: Progrès attendus. Gastroenterology Clinical Biology, 33, 811-817.

[3] Parkin, D.M. (2001) Global cancer statistics in the year. Lancet Oncology, 2, 533-543. doi:10.1016/S1470-2045(01)00486-7

[4] Hill, C. (2008) Doyon. La fréquence des cancers en France en 2005 : Évolution de la mortalité depuis 1950 et résumé du rapport sur les causes de cancer. Bull Cancer, 95, 5-10.

[5] Njonou, J., Kupfer, B., Kochan, B., Zekeng, L., Kaptue, L. and Matz, B. (2002) Hepatitis C virus infection and genotypes among human immunodeficiency virus highrisk group in Cameroon. Journal of Medical Virology, 66, 179-186. doi:10.1002/jmv.2128

[6] Zerbou, E.K., Dalekos, G.N., Boumba, D.S. and Tsianos, E.V. (2001) Value of anti-HBc screening of blood donors for prevention of HBV infection: results of a 3 year prospective study in Northwestern Greece. Transfusion, 41, 652-658. doi:10.1046/j.1537-2995.2001.41050652.x

[7] Mbendi Nlombi, C., Longo-Mbenza, B., Mbendi Nsukini, S., Muyembe Tamfum, J.J., Situakibanza Nanituma, H. and Vangu Ngoma, D. (2001) Prévalence du vih et l'antiggène HBs chez les donneurs de sang, risque résiduel de contamination chez les receveurs de sang à Kinshasa-Est, République Démocratique du Congo. TropMédecine Tropicale, 61, 139-142.
[8] Mbanya, D.N., Takam, D. and P Ndumbey, P.M. (2003) Serological findings amongst first-time blood donors in Yaounde, Cameroon: Is safe donation a reality or a myth? Transfusion Médecine, 13, 267-273. doi:10.1046/j.1365-3148.2003.00453.x

[9] Zekeng, L. and Kaptue, L. (1990) Serologie HIV et portage de l'antigene HBs et Hbe chez les donneurs de sang au CHU de Yaounde Cameroun. Annales de la Societé Belge Médecine Tropicale, 70, 49-53.

[10] Meffre, C., Le Strat, Y., Delarocque-Astagneau, E., Lemasson, J.M., Coste, D., Steinmetz, J., Antona, D., Dubois, F., Warszawski, J., Meyer, J.F., Leiser, S., Giordanella, J.P., Gueguen, R., Landau, A. and Desenclos, J.C. (2006) Prevalence of hepatitis B in France. 41th EASL Annual Meeting, 26-36 April, Vienne, 2003-2004.

[11] Ouattara, S.A., Meite, M., Akran, V., Gody, M. and Manlan, L.K. (1990) The G. Increase of the prevalence of hepatitis B virus surface antigen related to immunodeficiency inherent in acquired immune deficiency syndrome (AIDS). Journal of Acquired Immune Deficiency Syndromes, 3, 282-286.

[12] Moreira Diop, T. (2003) Atelier sur introduction des nouveaux vaccins dans PEV en Afrique francophone, révision des connaissances et considération des besoins en formation. Saly, Sénégal.

[13] Berrajah-Fki, L., Ben Halima, S., Guermazi, F., Hammami, A. and Karray-Hakim, H. (2006) Signification du profil sérologique “anticorps anti HBc isolés” chez 284 patients suspects d'être infectés par le virus de l’hépatite B. Annual Biology Clinical, 64, 451-455.

[14] Morris, S., Stephen, S., Kelly, B., et al. (2007) Prise en charge de l'hépatite $\mathrm{B}$ chronique: Lignes directrices consensuelles. Conférence 4-5, Toronto, Canada.

[15] Degos, F. and Hépatite, B. (2004) Qui et quand vacciner? Tiré à part, Post U FMC-HGE 3-4, L26, 47-51.

[16] Caspari, G., Beyer, H.J., Elbert, G., et al. (1989) Unsatisfactory specificities and sensitivities of six enzyme immunoassays for antibodies to hepatitis B core antigen. Journal of clinical Microbiology, 27, 2067-2072.

[17] Hofer, M., Joller Jemelka, H.I., Grob, P.J. and Lüthy, R. (1998) Opravil mand the swiss HIV cohort study. Frequent chronic hepatitis B virus infection in HIV-infected patient positive for antibody to hepatitis B core antigen only. European Journal of Clinical Microbiology and Infectious, 17, 6-13. doi:10.1007/BF01584356 